\title{
Entre Frio, Gelo e Pinguins: 0 Que Mais Têm na Antártica?
}

\section{Cold, Ice and Penguins: What Else Have in Antarctica?}

\author{
Carina Petsch * \\ Paola da Costa Silveira * \\ Jefferson Cardia Simões ** \\ Roselane Zordan Costella ***
}

\begin{abstract}
Resumo:
O objetivo deste trabalho foi analisar a superação da percepção dos estudantes sobre o continente antártico. A ideia central é discutir algumas informações trazidas pelos próprios alunos e investigar sobre seu conhecimento sobre este continente. O método utilizado constitui em avaliar o pré-conhecimento, discutir sobre o assunto e consolidar o que foi estudado através de elaboração de vídeos em formato de jornal, novela, documentário ou musical. Os vídeos demonstram confusão entre características do Ártico e da Antártica quanto a presença humana e fauna. Todos os grupos acreditavam que não havia turismo, não citaram aspectos da flora e apresentavam dificuldades em diferenciar neve e gelo. Muitas dúvidas sobre a Antártica ainda permanecem entre os alunos, mas sem dúvida estes saíram do esquema "frio, gelo e pinguins".
\end{abstract}

* Doutoranda em Geografia - Universidade Federal do Rio Grande do Sul (UFRGS)

** Professor do Programa de Pós-Graduação em Geografia - UFRGS - Pesquisador do Centro Polar e Climático

*** Professora do Programa de Pós-Graduação em Geografia - UFRGS

\section{Abstract:}

The objective of this study was to analyze the students perception of the Antarctic continent. The central idea is to discuss some information brought by the students and investigate their knowledge on this continent. The method used is to assess the pre-knowledge, discuss it and consolidate what has been studied by preparing videos in newspaper format, novel, documentary or music. The videos show confusion between characteristics of the Arctic and Antarctic as human and wildlife presence. All groups believed that there was no tourism, not mentioned aspects of flora and had difficulties in differentiating snow and ice. Many questions about Antarctica remain among the students, but no doubt they went out of the scheme "cold, ice and penguins."

\section{Palavras-chave:}

Antártica,

Construção de conhecimento

Metodologia de ensino, Geografia.

Key-Words:

Antarctica, Construction of knowledge, Teaching methodology, Geography 


\section{INTRODUÇÃO}

\subsection{Partindo do Aluno}

Considerar e discutir o que os alunos já sabem sobre determinado assunto, é uma forma de tornar a aula mais interessante e de fazer o aluno se sentir interessado no processo de ensino-aprendizagem. $\mathrm{O}$ ensino [de Geografia] visa a aprendizagem ativa dos alunos, atribuindo assim grande importância aos saberes, experiências, significados que esses alunos já trazem para a sala de aula (CAVALCANTI, 1998). Contudo, alguns aspectos devem ser considerados ao trabalhar o continente Antártico: provavelmente nem professor e nem aluno foram àquele continente, ou conhece alguém que tenha ido; não é um assunto frequentemente trabalhado, talvez por que os professores não saibam como ensinar, não possuem informações suficientes para discutir o assunto ou não está presente no livro didático; por outro lado, os filmes fornecem valiosas informações para o conhecimento dos alunos sobre a Antártica; as informações passadas pela mídia nem sempre são totalmente verídicas, mas correspondem a maior fonte de informações.

Costella (2008) salienta que quando um aluno precisa projetar a imagem de um espaço distante de sua realidade, o mesmo trará experiências e estruturas internalizadas de tudo o que viu, sentiu, suas apropriações acerca de determinado ambiente. Piaget (1996) ressalta que com essas condições, os alunos podem substituir objetos ausentes por representações, podem retratar outras características e delas tirar ações possíveis e reagrupando assim informações. No caso da Antártica, ainda existem muitos mitos e informações incoerentes, é muito importante trazer o conhecimento prévio desses alunos e a partir daí, discutir "velhas" informações e levantar novos dados, recriando sua representação do que realmente a Antártica têm, saindo da resposta: "frio, gelo e pinguins".

Assim, mesmo sem conhecer a Antártica, eles serão capazes de representar (Espaço Mentalmente Projetado) o cenário desse continente, através de outras experiências, de informações que leu, ouviu ou visualizou. Costella (2008) define o Espaço Mentalmente Projetado como modo que o aluno enxerga um espaço que está em sua mente, no seu imagético, por meio de ações e coordenações de ações perante conceitos de um espaço ausente concreto, mas presente na sua capacidade de projetar.

\subsection{Construção do Conhecimento}

Após considerar o conhecimento prévio dos alunos é preciso salientar que deve haver discussão e apresentação de novas informações acerca da Antártica, passando por um processo de assimilação e acomodação dos dados já apresentados e dos novos conceitos.

O próprio Piaget (1996) define a assimilação e acomodação como:

\footnotetext{
... assimilação é uma integração às estruturas prévias, que podem permanecer invariáveis ou são mais ou menos modificadas por esta própria integração, mas sem descontinuidade com o estado precedente, isto é, sem serem destruídas, mas simplesmente acomodando-se à nova situação. (PIAGET, 1996).
}

Ou seja, quando o pesquisador introduz novas informações e indaga os alunos sobre aspectos físicos (temperatura, relevo, solos) e a importância do continente antártico no sistema oceânico, climático, global, os alunos se deparam com esse processo de assimilação de conhecimento prévio com acomodação dos novos dados apresentados. Assim, os alunos vão formando novos esquemas, que continuamente são modificados e reformulados, quando surgem dúvidas, novas leituras sobre o assunto em questão. É um processo contínuo, onde se forma um esquema (estado de equilibrio) e é reformulado quando novos estímulos são apresentados aos alunos.

Qualquer conteúdo compreendido em sala de aula é abstraído em patamares diferentes conforme o nível de complexidade enfrentado, sendo que em cada patamar são reorganizadas e refletidas, para que se transformem em conhecimento. Quando o aluno age sobre o objeto ele toma consciência desta ação, construindo novas leituras (COSTELLA, 2011). Assim, ao se deparar com novos estímulos, dados sobre a Antártica, os alunos podem chegar a reflexões mais profundas, do que afirmar que é frio, tem pinguim, não tem moradores e somente pesquisadores. Piaget (1972) ressalta que a abstração consiste em acrescentar relações ao dado perceptivo e não apenas em extraí-las.

\subsection{Uso da Tecnologia em Sala de Aula}

Atualmente a tecnologia ganha espaço no ambiente de aprendizagem da Geografia, sendo os equipamentos de informática, a internet com acesso rápido em celulares, as imagens de satélites e a acessibilidade ao Google Maps e Google Earth os principais elementos (CAVALCANTI, 1998). Num momento onde o aparato tecnológico se faz presente no cotidiano do adolescente, deve-se usar esse que- 
sito para ajudar no processo de aprendizagem. O celular não deve ser visto como inimigo, mas inserido na aula.

Além disso, alunos curiosos e motivados facilitam o processo, estimulam as melhores qualidades do professor, tornam-se interlocutores lúcidos e parceiros de caminhada do professor-educador (MORAN, 2000). De acordo com Callai (1999), o professor precisa fazer da Geografia uma disciplina interessante. Uma disciplina que esteja ligada à vida do aluno, em vez de trabalhar com dados alheios a eles.

Com base no que foi exposto, a ideia central é discutir algumas informações trazidas pelos próprios alunos e aprofundar seu conhecimento sobre este continente. $\mathrm{O}$ objetivo dessa pesquisa foi produzir vídeos, com alunos de primeiro ano do ensino médio, sobre o continente Antártico, concretizando aquilo que aprenderam durante a discussão anterior sobre Antártica.

\section{MATERIAIS E MÉTODOS}

A pesquisa foi aplicada com 65 estudantes de primeiro ano de ensino médio politécnico, da Escola Estadual de Educação Básica Presidente Roosevelt, localizada em Porto Alegre, RS. Basicamente o trabalho foi baseado em três etapas:

a. Conhecimento preliminar: Primeiramente os alunos foram divididos em grupos de 5 indivíduos e convidados à escreverem num mapa da Antártica, informações, frases, palavras, conceitos que remetam o continente Antártico;

b. Verdade ou mito: Num segundo momento, com base no que foi relatado pelos alunos, foram escolhidas algumas informações e discutidas com propósito de classificá-las como verdade ou mito;

c. Produção do vídeo: cada grupo escolheu uma ou mais informações, das que foram discutidas no item 2 (Verdade ou Mito), para ser relatada no vídeo. Foi proposto que cada grupo simulasse um ambiente de um programa de entretenimento (comédia, novela, jornal ou música). $\mathrm{O}$ vídeo deveria ser curto, de aproximadamente 2 a 3 minutos e foi gravado e editado pelos alunos.

Assim, se pretendeu desenvolver o método de pesquisa com base no processo de construção do conhecimento de Piaget (1972). Por essa razão o conhecimento preliminar do aluno foi considerado, buscando um posterior desequilíbrio diante de perguntas e indagações feitas pelos pesquisadores. Assim, enfrentando um momento de acomodação e assimilação, e estabelecendo um novo esquema de informações sobre a Antártica (Figura 1).

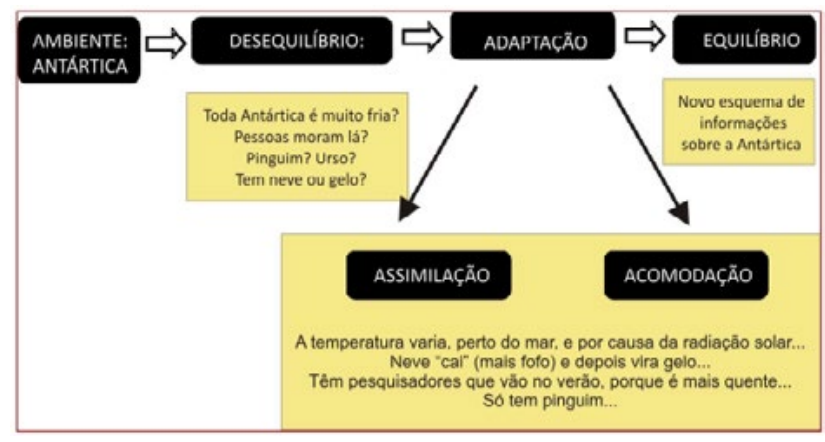

Figura 1: Fluxograma adaptado a partir do processo de construção de conhecimento, com observações de como foi utilizado nessa pesquisa. Fonte: Piaget (1972)

\section{RESULTADOS E DISCUSSÕES}

\subsection{Conhecimentos preliminares sobre a Antártica}

\subsubsection{Distância entre a Antártica e Porto Alegre}

Um dos questionamentos feitos pelos pesquisadores, foi a distância entre Porto Alegre e a Antártica, e entre Porto Alegre e o extremo norte do País. Essa discussão foi levantada para analisar se eles possuem noção do quanto a Antártica está próxima do Brasil. A Antártica é o segundo continente mais próximo do país.

Porto Alegre (RS) está a somente $3.600 \mathrm{~km}$ da antiga Estação Antártica Comandante Ferraz. Ou seja, Boa Vista (capital de Roraima) está mais longe $(3.788 \mathrm{~km})$. Quando questionados sobre o que é mais perto de Porto Alegre, a maioria demonstrou não saber precisamente a localização de Manaus e do norte do País. Três de nove grupos apontaram valores corretos na distância entre Porto Alegre e a Antártica (Quadro 1).

É interessante salientar que dois grupos consideraram seus conhecimentos prévios de cartografia e fizeram cálculos de escala para descobrir o valor de distância.

Quadro 01: Distância apontada pelos alunos entre Porto Alegre e a Antártica (antiga Estação Antártica Comandante Ferraz - Península Antártica)..

\begin{tabular}{|c|c|}
\hline Turma & $\begin{array}{c}\text { Distância de Porto } \\
\text { Alegre até a Antártica } \\
\text { (km) }\end{array}$ \\
\hline $\mathbf{1}$ & 4700 \\
\hline $\mathbf{1}$ & 4285 \\
\hline $\mathbf{1}$ & 3900 \\
\hline $\mathbf{2}$ & 5000 \\
\hline $\mathbf{2}$ & 3500 \\
\hline $\mathbf{3}$ & 3600 \\
\hline $\mathbf{3}$ & 2000 \\
\hline 3 & 4300 e 4600 \\
\hline & 3725 \\
\hline
\end{tabular}




\subsubsection{Conbecimentos preliminares sobre a Antártica: aponta- mentos dos alunos}

É importante considerar as informações que provêm dos filmes como fonte de conhecimento dos alunos sobre a Antártica, já que nenhum deles relatou que obteve informações com base em alguma fonte formal (ivros, mapas). Foi possível ouvir de muitos alunos frases como: "eu vi no Discovery..."; "o filme Era do Gelo falava que tinha mamutes...”; "o filme Happy Feet era na Antártica? (Figura 02-A e B); "o Globo Repórter disse que lá têm pesquisadores...". Assim, pode-se perceber que todos possuíam alguma informação sobre o continente, entretanto apresentaram muitas dúvidas, sendo assim necessário questionamentos e reflexões feitas pelos pesquisadores para repensarem e também para adquirirem mais informações.

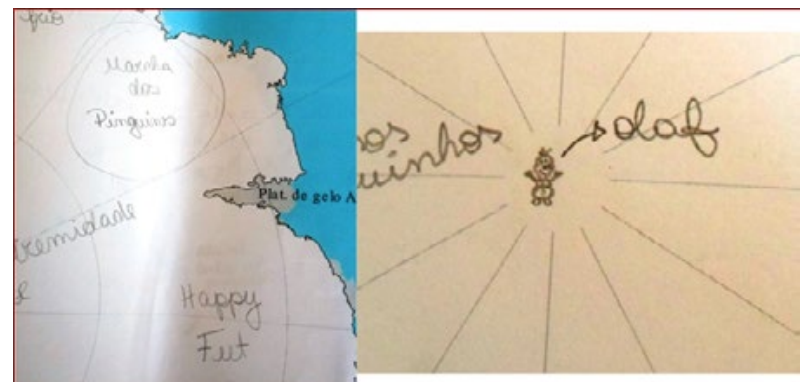

Figura 02: A-Citação de filmes como informação trazida pelos alunos B- Olaf é o nome de um boneco de neve do filme "Frozen: uma aventura congelante"

Fonte: Acervo dos autores

\section{- Relação Brasil e Antártica}

A maioria dos alunos disse que existe relação entre Brasil e Antártica devido à movimentação de ventos frios ( $\mathrm{Fi}$ gura 03-A) e ao aumento do nível do mar (Figura 03-B), em caso de derretimento do gelo. Curiosamente, eles relatam a questão do aumento do nível do mar, mas não estabelecem relações de circulação oceânica (correntes frias e quentes) entre as regiões polares e os trópicos. Ou seja, eles possuem uma noção sistêmica do Planeta, só precisam aprofundar esse conhecimento.

Quase por unanimidade, acreditavam que a Antártica teria menos de $90 \%$ do volume de gelo do planeta. Dessa forma, talvez o desinteresse pelos estudos da Antártica esteja exatamente no sentido de não compreender sua importância global, num sentimento de distanciamento, por não associarem as relações que mudanças na Antártica podem trazer para seu cotidiano.

- Biodiversidade
A Antártica não possui flora de grande porte, só líquens, musgos e duas espécies de gramíneas, talvez por isso nenhum dos grupos citou a presença de flora. Existe uma visão, entre esses alunos, de que a Antártica é um continente totalmente desprovido de vida vegetal, sendo uma região totalmente coberta por neve e gelo, sem condições climáticas para qualquer desenvolvimento vegetal. Quanto aos animais, percebe-se que há uma aceitação de que estes podem se adaptar a condições frias. Entre os desenhados estão pinguins, focas, baleias e leões-marinhos. Vários grupos confundem a localização geográfica de pinguins e ursos polares (Figura 04 A e B).

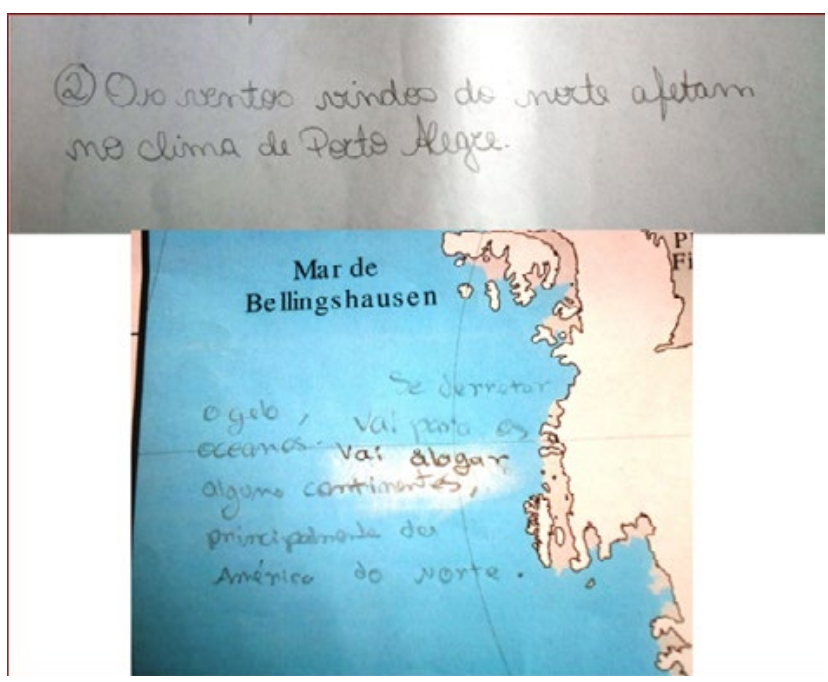

Figura 03: A- Relação climática entre Porto Alegre e a Antártica; B-Relação do degelo e aumento do nível médio dos mares. Fonte: Acervo dos autores

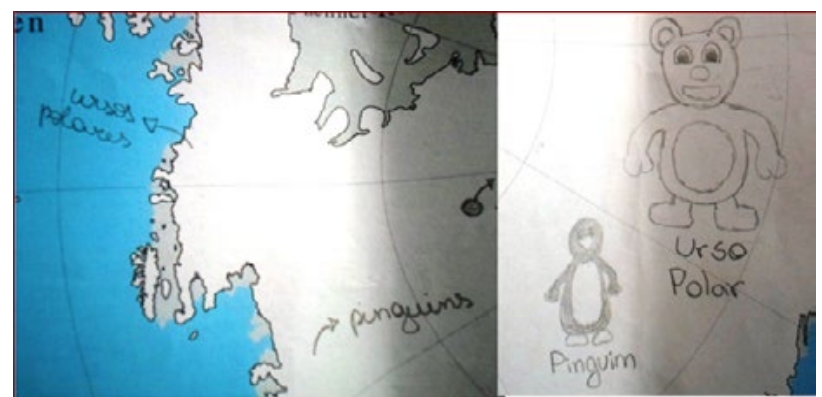

Figura 04 (A e B): Pinguins e ursos polares representados na Antártica. Fonte: Acervo dos autores

- Neve e gelo

Alguns possuem noção de que a neve é algo menos compacto que o gelo, portanto concluíram que somente pode ocorrer precipitação de neve, e que o gelo se forma posteriormente. Por outro lado, alguns grupos representaram toda Antártica coberta por neve (Figura 05-A), ou dese- 
nharam um cubo de gelo em algumas porções do continente (Figura 05-B). Muitos colocaram que na Antártica têm geleiras, mas não souberam definir o que é geleira. Percebe-se uma grande miscelânea de conceitos relacionados a Criosfera, que poderiam serem debatidos durante a aula de ciclo hidrológico, por exemplo, no que tange a diferença de neve e gelo, derretimento de geleiras.

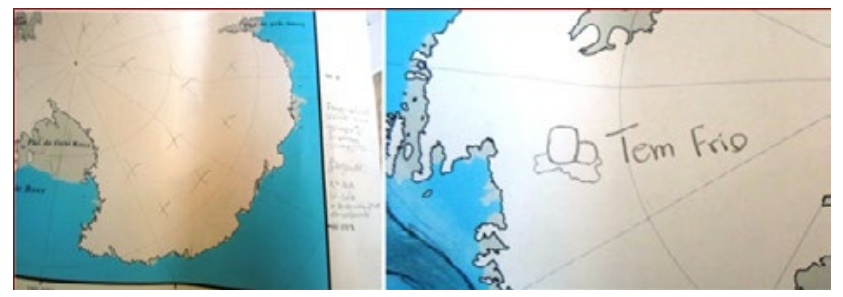

Figura 05: A-representação de neve e gelo na Antártica e (B) desenho de cubo de gelo.

Fonte: Acervo dos autores

\section{- Temperatura}

Cerca de $80 \%$ dos alunos apontaram diferenças de temperatura no continente, entre a porção central e a próxima ao oceano. Um grupo denotou que a porção central do continente era mais fria porque recebia menos radiação solar durante o ano (Figura 06-A e B), e outro grupo apontou a proximidade ao mar, como um fator de aumento da temperatura. Outros grupos fizeram essa relação inversa, considerando a área próxima ao mar fosse a mais fria. Esses dados apontam deficiência nas aulas sobre rotação do Planeta, estações do ano e sobre fenômenos de troca de energia entre oceano e continentes.

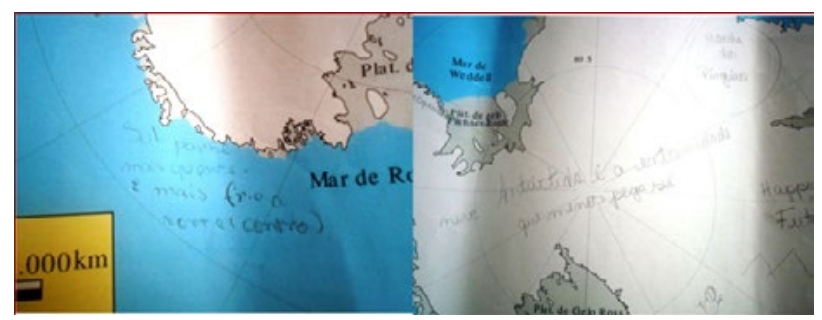

Figura 06: Relação temperatura, radiação solar e distância do mar. Salienta-se que na figura $A$, os alunos apresentam dúvidas quanto a orientação de norte e sul.

Fonte: Acervo dos autores

Apesar de fazerem uma relação correta entre a radiação solar e a temperatura, não demonstraram propriedade ao relatar esses valores de temperatura. Acreditavam que a temperatura sempre era menor que $-20^{\circ} \mathrm{C}$. A maioria dos grupos não considerou a sazonalidade na Antártica, como fator de variações de temperatura.

\section{- Presença humana}

Muitos relataram a presença do povo Inuit na Antártica (Figura 07-A). Assim, como no caso dos ursos polares, pode-se observar a confusão entre as duas regiões polares. Quase todos apontam a presença de pesquisadores, e sabem que o Brasil possui pesquisas na Antártica.

Muitos desenharam centros de pesquisa por toda Antártica, isso aponta que os alunos acreditam que há estações espacialmente localizadas em todo continente, e que seu número é muito maior ao que realmente existe.

Quase todos os grupos julgaram que não há turismo na Antártica (Figura 08-B). Apesar do turismo na Antártica ser ainda muito caro, nos últimos anos, várias operadoras se aventuram na região a cada ano. No momento, 35 operadoras de 10 países diferentes atuam na Antártica com navios de turismo, principalmente na costa oeste da Península Antártica. As visitas se concentram nas zonas livres de gelo entre novembro e março.

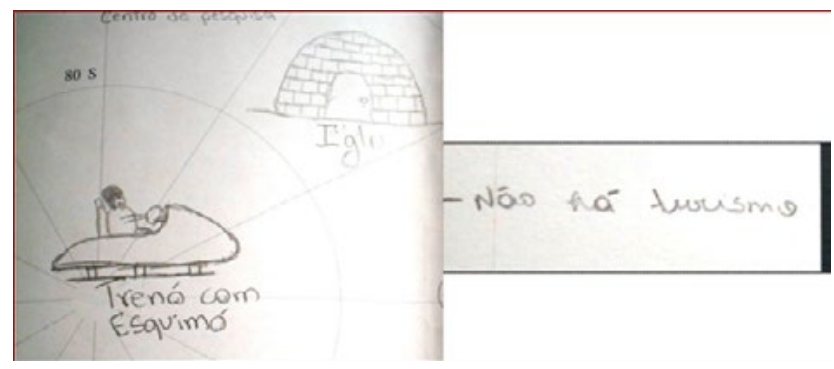

Figura 07: A-Alunos desenharam iglus e esquimós, relatando confusão entre o polo norte e sul. B-Alunos que escreveram no mapa, que não havia turismo.

Fonte: Acervo dos autores

\section{- Relevo}

A maioria relatou que não existe um lugar totalmente plano, por isso concluíram que na Antártica também deveria ter variações na configuração do relevo. Contudo, não souberam relatar onde (Figura 08-A) existiriam montanhas e outras feições topográficas ou qual sua altitude (Figura 08B). Na verdade, o grande problema está em que os alunos considerarem a Antártica como um continente homogêneo, sem plantas, sem relevo, sem variações de temperatura, sem habitantes. É necessário aprofundar esses temas, frisando os detalhes do continente, desconstruindo essa visão tão uniforme.

-Se você pudesse morar na Antártica, em qual parte seria?

Essa pergunta hipotética foi feita pelos pesquisadores. A maioria dos alunos apontou a Península Antártica 
(Figura 9-A), e entre as justificativas têm-se a proximidade à civilização ou por acreditarem ser um lugar mais quente. $\mathrm{Ou}$ então, as margens do continente (Figura 9-B), também por acreditarem ser menos frio que o interior do continente.

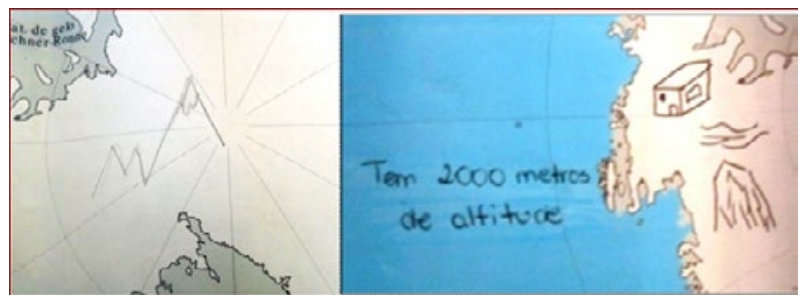

Figura 08: A-Representação de montanhas na Antártica; B-único valor de altitude relatado no trabalho inicial.

Fonte: Acervo dos autores

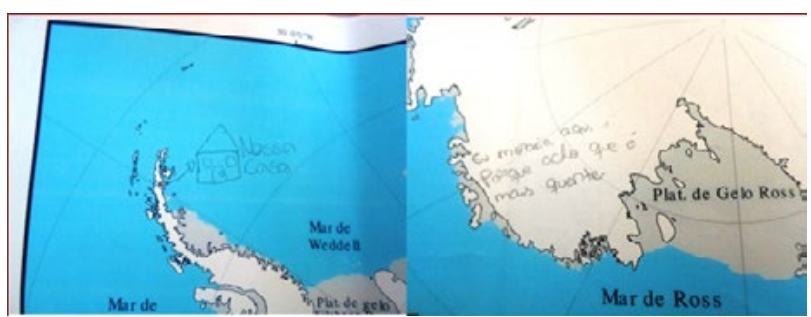

Figura 9: Representação (A) e justificativa (B) de possível moradia na Península Antártica.

Fonte: Acervo dos autores

\subsection{Equilíbrio: produção de vídeos}

Citar algo sobre a baixa temperatura e apresentar o formato de jornal foram características comuns a quase todos os vídeos. Basicamente, os vídeos apresentaram determinado aluno como repórter, que vai à Antártica e descreve as características do tempo, ou então através da previsão meteorológica para a área em questão. Pode-se dizer que a antiga informação (de que a Antártica é fria, mas não sabiam dizer o quanto), foi questionada e discutida levando-os a um novo patamar de conhecimento, no momento em que identificaram os valores de temperatura e entenderam como ocorre a sua espacialização no continente. $\mathrm{O}$ turismo no continente gelado também chamou a atenção dos alunos. Demonstraram interesse em saber qual o valor desses pacotes turísticos, o que incluía, se o Brasil possui empresa que realiza essa viagem.

Dois grupos simularam uma entrevista com possíveis turistas na Antártica, contudo estes estavam passeando livremente pelo ambiente antártico sem nenhuma condição de segurança ou respeito para com a fauna e flora local. $\mathrm{Na}$ verdade, o turismo é responsável, e respeita as condições do ambiente Antártico.

Outro ponto que merece atenção é a dificuldade de entender as conexões ambientais do planeta, ao considerar a relação de Porto Alegre com a Antártica. Em alguns vídeos eles ressaltaram a distância entre esses pontos, e a dificulda- de de comunicação entre o possível repórter na Antártica e os jornalistas do estúdio de Porto Alegre. Enquanto que na etapa 1 (determinação sobre o que sabiam sobre a Antártica), muitos citaram os ventos frios da Antártica que atingiam Porto Alegre, e o aumento do nível do mar, nos vídeos essas informações não foram salientadas.

Um grupo produziu um vídeo no estilo documentário, sobre os animais da Antártica, mostrando fotos e informações e curiosidades sobre essa fauna, sendo que novamente a flora não foi considerada. Ressalta-se que esses alunos tiveram a curiosidade de pesquisar mais sobre o assunto, e entender a importância do ambiente antártico para a sobrevivência desses animais. Se antes da pesquisa eles sabiam da presença dos animais, agora possuem uma noção da sua relação com esse ambiente.

Outro vídeo tem como cenário um iglu, corroborando para a confusão entre as duas regiões polares, mesmo após ser trabalhado em sala de aula que os Inuits são habitantes do hemisfério norte. Assim, como proposta de trabalhos futuros, é necessário de comparar os dois ambientes polares, evitando estudo separado da Antártica.

Mesmo que só como curiosidade, o uso dos topônimos "Antártica" e "Antártida", devem ser discutidos. Alguns possuem uma ideia de que sejam lugares diferentes.

\section{CONSIDERAÇÕES FINAIS}

A mobilização dos alunos, ao desenharem geleiras, ou procurarem mapas para servir de plano de fundo dos vídeos, sua motivação ao ir até o auditório do colégio para gravar o vídeo, ir até a biblioteca buscando informações, gravar na chuva para simular a precipitação de neve, demonstrou o poder das tecnologias para tornar a aula motivante e envolvente, e afirmou a aplicabilidade do método proposto nesse estudo.

Por outro lado, as dificuldades para se ensinar a Geografia das regiões polares configuram um desafio, independentemente do nível escolar. Um primeiro passo pode ser criar maneiras de inserir o tema na sala de aula, mostrando sua importância na relação Brasil - Antártica. Também se pode trazer filmes ou documentários curtos com essa temática, ou então apresentando curiosidades sobre a Antártica, experiência de pessoas que já estiveram no continente.

Contudo, dos estudantes participantes desse estudo, foi possível perceber um processo de construção de conhecimento, saindo do velho esquema "Frio, gelo e pinguins".

\section{AGRADECIMENTOS}

À Escola Estadual de Educação Básica Presidente Roosevelt, Porto Alegre/RS, por ceder seus estudantes para 
a aplicação desta pesquisa.

\section{REFERÊNCIAS BIBLIOGRÁFICAS}

ANTUNES, C. (Coord.). Geografia e didática. Petrópolis, RJ: Vozes, 2010. (Coleção Como Bem Ensinar).

CALLAI, H. C. O ensino de geografia: recortes espaciais para análise. In: CASTROGIOVANNI, A. C. (org.). Geografia em sala de aula: práticas e reflexões. 2. ed. porto Alegre: UFRGS, 1999.

CAVALCANTI, L. S. Geografia, Escola e Construção de Conhecimento. Campinas: Papirus, 1998.

COSTELLA, R. Z. O significado da construção do conhecimento geográfico gerado por vivências e por representações espaciais. Tese de doutorado. UFRGS, Porto Alegre, 2008.

COSTELLA, R. Z. Competências e habilidade no contexto da sala de aula ensaiando diálogos com a teoria Piagetiana. Cadernos do Aplicação, Porto Alegre, v. 24, n. 1, jan./ jun. 2011.

MORAN, J. M.et al. Novas tecnologias e mediação pedagógica. 6. ed. Campinas: Papirus, 2000.

PIAGET, J. Epistemologia Genética. São Paulo: Martins Fontes, 1972.

PIAGET, J. Biologia e Conhecimento. $2^{\mathrm{a}}$ Ed. Vozes: Petrópolis, 1996.

\section{Correspondência dos autores:}

\author{
Carina Petsch
}

e-mail: carinapetsch@gmail.com

Paola da Costa Silveira

e-mail: paoladcs@gmail.com

Jefferson Cardia Simões

e-mail: jefferson.simoes@ufrgs.br

Roselane Zordan Costella

e-mail: ro.paulo@terra.com.br

Artigo recebido em: 18/05/2015

Revisado pelo autor em: 23/06/2016

Aceito para publicação em: 05/10/2016 